three years, I think it will be acknowledged that the whole tells, with considerable significance, against those who look to climatic influences as being the principal cause of enteric fever in India.

The believers in the climatic origin of cases of enteric fever in India very correctly point out, that the principal victims of this fever are young soldiers, with little Indian service; and that the older men, with an Indian service of four or more years, are rarely sufferers from it. Without gainsaying this observation, or attempting to account for it, I would simply say that, for a space of five years, Assirgarh has been occupied by successive batches of young and unseasoned soldiers without the occurrence among them of any type of fever, other than the mildest form of ague.

The climate of Assirgarh is no better than that of many other stations in the Bombay Presidency, where enteric fever is of only too frequent occurrence; but, as I have already said, its isolated situation, and the nature of its surroundings, lessen to a very great extent its liability to fæcal contamination of any sort; and herein lies (as it seems to me) the reason for the immunity it enjoys from the presence of enteric fever.

Before bringing these brief remarks on an important subject to a conclusion, and notwithstanding the evidence I submit I have adduced in favour of enteric fever being a fæcal disease in India as elsewhere, I would say that, personally, I am by no means convinced that a fæcal impurity must exist before cases of enteric fever can occur in India. I have seen many outbreaks of enteric fever, between which, and a fecal impurity, it was not possible to trace any connection and where, on the contrary, many things favoured the view of some climatic influence being the fons et origo mali.

The facts, however, which I have gathered from the sick-returns of this station, seem to me to point so very significantly in favour of the view which considers "enteric fever to be a fæcal disease in India as elsewhere", that I have felt it to be incumbent on me to place them on record.

\section{ON TRANSFUSION.}

BY J. F. LE PAGE, L.R.C.P.E., etc., Durham.

CoNvinced that, in the conservative practice of the future, transfusion will hold a place of no little importance, and will be more and more extensively resorted to, and seeing that the means at present at our disposal for the performance of the operation are not altogether satisfactory, I have devised an apparatus in which there is an endeavour to combine absolute safety with great facility in use.

Of the transfusors which have been at our service, that of Dr. Aveling is, perhaps, all things considered, the most serviceable. But it has the disadvantage of requiring very complex manipulation. To put it concisely, each of them requires, in its use, for the surgeon to be aided by skilled assistance, whilst at the same time, there is no safegnard against the injection of a minute quantity of air, however careful an adept the operator may be, an accident which in all probability would prove fatal to the patient.

The accompanying illustration shows how these disadvantages are overcome. One hand alone is needed to operate the transfusor, and the other hand is at liberty to attend to the efferent tube, whilst the attention of the surgeon may be divided between the recipient and the donor of the blood. If any portion of air should at first remain adherent, and, of course, unseen, on the inner surfaces of the tubes, and, during the passage of the blood, be carried along with the stream, its course is with certainty arrested by the glass air-receiver, into which it must rise.

The case contains the apparatus, knife, forceps, and a small bottle, which latter is intended to hold a compound powder composed, say, as follows : carbonate of soda, ten grains phosphate of soda, two grains ; chloride of sodium, thirty grains. One fourth of the powder should be dissolved in about two and a half ounces of water at a temperature of $100^{\circ} \mathrm{Fahr}$., a few drops of alcohol may be added, and the vessel containing the solution placed in another vessel partly filled with water at a temperature somewhat higher. Then, having attached the receiving and delivering tubes, the two extremities of the instrument must be placed in the inner vessel with the air chamber downwards. Now press the lever, press the elastic ball, release the lever, release the elastic ball, and after repeating that process once or twice, turn both taps. It is now ready for use. Raise the patient's arm to the horizontal position, so as to facilitate the transmission of blood to the heart, and having inserted both tabes, one into the supplying vein, and the other into the receiving vein, the right median basilic is perhaps the best, turn the taps, and in the same order press the lever, press the ball, release the lever, release the ball, and so on. Precisely one quarter of an ounce passes out each time. It is expedient, having commenced the transmission of blood, to complete the process without arrest, lest coagula should form.

The apparatus is made by Messrs. Arnold and Sons, and their name is quite sufficient guarantee for excellence of workmanship. I must, however, say that my thanks are due to them for so faithfully, so well, and with such precision and care, elaborating from my drawings an instrument of some elegance.

A word as to the cases in which transfusion is indicated. $\mathbf{M y}$ special intention is that of supplying the obstetrician with a safe and easy means of transfusing blood after post partum hrmorrhage, where the diastaltic system is practically dead, and the heart is dynamically incapable of action in consequence of the absence of fluid to act upon. But transfusion is indicated in many other cases than that of uterine hæmorrhage leading to this condition. For instance, it is needed when after excessive hrmorrhage the vital fluid is not reproduced, and the nutritive process is so impaired that the persistent anzemia would be the forerunner of phthisis or other grave disease, did we not supply red corpuscles to carry oxygen, with which to re-establish those functions which are essential factors in the formation of hromoglobulin. And it is certainly indicated in some cases of hæmorrhage from the bursting of an aneurysm, or where a main artery has been divided; with its aid, life may at least be prolonged when the stomach and rectum refuse to retain nutriment in the exhaustion from marasmic disease.

It may also be resorted to in the asphyxia of new born infants, the injection being made through the umbilical vein, having previonsly allowed a little blood to escape from the umbilical artery. For this purpose a small quantity of blood taken from the placenta and defibrinated will answer very well. In chronic as well as in acute anæmia we may transfuse, for where the whole blood is altered by toxic or pathological causes, it is manifestly advantageous to impy toxic or patity by the admixture of healthy blood. It may also appear indicated after hæmorrhages from the stomach and intestines, hæmoptysis, and some surgical operations. I would go so far as to suggest, on physiological grounds, its occasional indication in hemorrhagic fever. In the young, who are robust, absorption and nutrition will soon replace the normal quantity of fluid, although for a time it will be inferior in quality to that which was lost, containing less than the due proportion of oxygen carried by the red corpuscles. In those previously suffering from anæmia, and in the aged whose blood is very slowly reproduced, it appears to me that the operation may, with very great promise, be repeated more than once at intervals of a few days. In cases of poisoning, when the nature of the poison is nnknown, or when an antidote would not be effective, or in pyæmia, might not occasionally a life be saved by alternate depletion and injections of pure blood? In epilepsy it has been used with marked success; and as in puerperal eclampsia we may presume an excess of carbonic acid and a deficiency of oxygen, may we not here also find it of no little service? I should remark that Prof. Schäfer has most conclusively shown that the action on the blood corpuscles of beef, peptones, and some other fluids, when used in lieu of blood, is most injurious.

It has been urged in disparagement of the operation that, during transfusion, very painful symptoms are experienced, followed after its performance by alarming prostration and hæmorrhagic fever. This we may admit as,'in some cases, substantially correct. But what is the cause of all this, but that the vital powers are so stimulated to reassert themselves that the heart and arteries, certainly with intermissions, are making very violent efforts to drive. along the small quantity of blood which the system contains?

The inference is clear, that this most valuable operation has not been so frequently performed as it should have been, and that many been so frequen lo immediate restoration of the failing powers of the heart and nervous gystem which it most strikingly effects.

The dangers incident to the operation are the injection of particles 
of air, and the formation of coagula. The first I have entirely overcome by the use of an air-receiver. The second, by preparing the blood of the donor before it is drawn from his vein. I have attested by repeated experiments that the administration of as large a dose of ammonis: and of a saline as can well be tolerated, ten minutes be: fore blood is allowed to flow, very effectively retards coagulation The transfusor may be used either to inject whole blood or defibrinated blood; or saline solutions may be substituted where vital fluid is not obtainable.

\section{NOCTURNAL ENURESIS TREATED .BY VOLTAIC ALTERNATIVES.}

BY JULIUS ALTHAUS, M.D., M.R.C.P.,

Senior Physician to the Hospital for Epilepsy and Paralysis, Regent's Park.

IN June 1882, I was consulted in the case of a boy, aged 15, who had suffered from incontinence of urine luring sleep, ever since he was nine years of age. He had been treated with belladonna and othier medicines without relief; and as he was about to enter a public school, where a continuance of this trouble might have been patticularly annoying, the parents were very anxious that something more should be done. The boy's general health was good, but he was considered a nervous child, and highly sensitive. There were no, a:carides, but he had a very long prepuce which could only with difficulty be retracted. There was, however, no suspicion of masturbation. Treatment by electricity having been recommended, I applied the middle-sized circular cathode over the region of the bladder, and the large oblong anode (five inches by two) to the lumbar portion of the spine. The current-strength 2.50 milli-amperes, for five minutes at a time. As after a few such applications no material benefit appeared to have been gained, I then added fifty voltaic alternatives produced in the metallic circuit. The night. after this was free from the usual annoyance, and the boy has made an apparently uninterrupted recovery.

Sir Henry Thompson, in his article on Disorders of Micturition in Quain's Dictionary of Mellicine, recommends the injection of a tcngrain solution of nitrate of silver to the prostatic portion of the urethra and the neck of the bladder, for that troublesome minority of cases in which belladonna has no influence; and he says not a single word about electricity. It appears to me, however, that the mode of using electricity which I have just described, and from which I have seen satisfactory results in a considerable number of cases, is much to be preferred, from being more managcable, and also painless. Nitrate of silver injeoted into the urethra of children, may cause considerable local pain and general systemic disturbance, more especially as these patients are generally found to have inherited the neurotic constitution, and to be unduly sensitive.

Seeligmüller and Erb likewise report good results from the use of electricity in enuresis. The former's method consists of the introduction of a wire-electrode, about one centimètre long, into the orifice of the urethra (whether male or female), this is connected with the negative pole of the secondary faradic current, the moistened anode being applied over the os pubis. Erb, in his recent Handbook of Electro-T'herapeutics (Leipzig, 1882, p. 680) recommends, in addition to an external application of faradism to the spine, the os pubis and the perinæum, the insertion of a wire electrode, two centimetres long, into the male urethra, while in girls a small spongeelectrode is applied between the labia, close to the orifice of the unetbira. He pronounces the results obtained by this method to be excellent. It will probably be allowed that the method I have described above, will, cateris paribus, be preferable to those of Seeligmüller and Erb, more especially in the case of girls.

The affection arises, according to Sir Henry Thompson (loc. cit. p. 984) not from inability of the bladder to retain a small quantity of urine but from its undue excitability and readiness to contract and there can be no doubt that in many cases such undue excitability, not perhaps so much of the bladder itself, as of its centres in the spinal cord, is at the bottom of the affection. It is in such cases that belladonna proves serviceable. 'In others, however, the exceedingly profotand sleep, which is so common in such patients, together. with debility of the sphincter of the bladder, or rather of its centre in the lumbar enlargement of the cord, must be considered as conducive to the disorder. In such cases belladonna fails.to reliove, while electricity, being a stimulant as well as a sedative appears suitable for both classes of cases; although more especially for the latter.

\section{ON A NEW FORM OF INTRA-UTERINE PESSARY.*}

\author{
BY JOHN G. NEVTTT, M.R.C.S.Eng., Chapel Allerton.
}

I IIAVE an old fashioned prejudice as to the sanctity of the intrahterine cavity, but experience has shown me cases, whose only hope of relief lay in the proper application of an intra-uterine support A very obstinate case of acute anteflexion, with bladder-symptoms, and mental trouble (which the pessaries I tried failed to relieve), set me to work, with the result I now bring to your notice. I was not, at that time, acquainted with the admirable instrument of Dr. Wynn Williams, or, possibly, I should have relinquished my self-imposed task as inventor, for the more agreeable, because less irksome, one of utiliser. However, having endured the pangs of maternity, it is now my pleasing duty to bring the offspring before you, and, like a fond parent, point out to you what I consider to be its superiority.

There are four main objects desirable in all pessaries : 1, efficiency when in situ; 2, few points for retention of secretion; 3 , ease of introduction; 4, ease of extraction. I claim for the pessary I show you all these desiderata, plus: a few other recommendations.

By the elasticity of the ring, it easily adapts itself to the surrounding parts, and thus takes a firmor hold. By means of the rubber bands, the position of the stem, in relation to the axis of the pelvis, can be altered as required. The spaces between the bands allow the free passage of vaginal injeotions, and thus ensure cleanliness. The bands are easily replaced if worn or broken. Each ring fits any stem. The ordinary Simpson's sound is the introducer. These advantages have only to be mentioned to recommend themselves.

I am sorry that the shortness of the time since the completion of the pessary, and iny not being connected with any hospital for women, prevents my being able to give you a long list of results; but, in the two cases in which I have tried it, it proved satisfactory. I wish to record my opinion that the cases in which intra-uterine stems are absolutely necessary, are not of frequent occurrence, and, in the necessary cases, they are not always permissible. There seems to be the same danger with surgeons as with nations, who, having a very efficient armamentarium, make a case to utilise it.

The pessary is made for me by Messrs. Mayer and Meltzer, to whom I have to express my indebtedness for valuable hints.

Dr. BARRON (Southport) said that the chief objection to the instrument described was, that the stem was not sufficiently firmly fixed, and might possibly slip out of place. The elastic bands allowed too much lateral and vertical motion; and thus by getting out of order the pessary might cause considerable mischief and difficulty.

Dr. DeWAR (London) thought Mr. Nevitt's instrument had no advantage over those of Routh, Wynn Williams, or Meadows and Bisichs : it was too heavy and too long in the stem. $\Lambda$ stem should never reach the fundus uteri, as it often did harm. The advantage of Mr. Nevitt's instrument might be the movable cross-bar of his transverse band.

Dr. MCARThur (Anstruther) considered the pessary to be of very ingenious construction; and that, where an intra-uterine stem was absolutely necessary, it was likely to prove very useful. He objected, however, to the length of the stem, owing to the danger which might however, to the length or even penetration of the fundus. With care in the adaptation of the length of the stem, the instrument was likely to be both safe and efficient.

Dr. CullingwoRTH (Manchester) said one advantage of bringing new instruments before one's professional brethren was that, in this way, improvements were often suggested in points of detail. Doubtless the stem in the instruments exhibited was unnecessarily and undesirably long; but that Mr. Nevitt could very easily have altered. He thought the pessary was ingenious, and possessed many advantages; and he certainly should try it when an opportunity offered, although he quite agreed with Mr. Nevitt that the number of ex excedingly small.

Mr. Doxovas (Whitworth) had much pleasure in seeing that the use of the intra-uterine stem was being improved off the face of the ine Manchester meeting, a stem was brought forward as arthe for all the ills that the uterus was heir to. At Bath, also, a panilar stem was brought forward. In both instances, he opposed a similar stem Mr. Nevitt deserved the thanks of the section for the very moderate way in which he had brought the subject forward; and for

* Read in the Section, of Obstetric Medicine at the Annual Meeting of the British Medical Association in Worcester, August 1882 . 